\title{
Pretreatment with bacterial components promotes DSS-injured colonic epithelial repair through the activation of STAT-3
}

\author{
ZHENGLEI XU, BIHONG LIAO, RU ZHANG, RUIYUE SH and LISHENG WANG \\ Department of Gastroenterology, Second Clinical Medical College, Jinan University, \\ Shenzhen People's Hospital, Shenzhen, Guangdong 510632, P.R. China
}

Received March 1, 2016; Accepted January 31, 2017

DOI: $10.3892 / \mathrm{mmr} .2017 .6812$

\begin{abstract}
Bacterial protection and epithelial repair are important against inflammatory bowel disease (IBD). The present study was designed to examine the effects of different bacterial components on the repair of normal and dextran sodium sulfate (DSS)-treated colonic epithelial cells and the corresponding mechanisms. Human colonic epithelial cells (HT-29) were pretreated with various doses of LPS or CpG-dsDNA for $24 \mathrm{~h}$ and then treated with or without DSS for another $24 \mathrm{~h}$. The epithelial repair was assessed by video analyses following mechanical injury. The epithelial expression of cluster of differentiation (CD) 40 was assayed using flow cytometeric analysis. The production of interleukin (IL)-6 and tumor necrosis factor (TNF) in the cell culture medium were measured using ELISA. The expression of p38 mitogen-activated protein kinase (MAPK) and signal transducer and activator of transcription (STAT)-3 were examined using western blot analysis and reverse transcription-quantitative polymerase chain reaction analysis. MAPK and STAT-3 inhibitors were also administrated to observe signaling-mediated repair. The results showed that pretreatment with lipopolysaccharide (LPS) or CpG-dsDNA promoted epithelial repair of the DSS-treated cells. The promoting effects were associated with the downregulation of CD40 molecules, inhibition of the p38 MAPK/TNF $\alpha$ pathway and activation of the STAT3/IL-6 pathway. The STAT3 inhibitor abrogated the protective effects of LPS and CpG-dsDNA on wound repair. These results demonstrated that LPS and CpG-dsDNA induced preadaptation to DSS injury. This preadaptation was accompanied by the activation of STAT-3. Thus, bacterial components may be used as a strategy for the therapeutic prevention of IBD.
\end{abstract}

Correspondence to: Dr Lisheng Wang, Department of Gastroenterology, Second Clinical Medical College, Jinan University, Shenzhen People's Hospital, 1017 Dongmen North Road, Shenzhen, Guangdong 510632, P.R. China

E-mail: maxwangls@sina.com

Key words: cluster of differentiation 40, inflammatory bowel diseases, toll-like receptor, signal transducer and activator of transcription 3

\section{Introduction}

The most prevalent inflammatory bowel diseases (IBDs) include ulcerative colitis and Crohn's disease, which are induced by several factors, including genetic defects, environmental stimuli, immune abnormalities and microbiota (1). Susceptible hosts may be associated with defective bacterial clearance, leading to exaggerated immune responses and subsequent tissue damage; substantial evidence has shown that abnormal innate immunity, specifically in microbial recognition and its subsequent elimination, are involved in the development of IBD $(2,3)$. IBD exhibits an exaggerated T cell response (Th1/ Th17) towards luminal microbiota, which results in the breakdown of mucosal tolerance to enteric bacteria (4).

Toll-like receptors (TLRs) are involved in the development of innate immunity and subsequent development of adaptive immunity for the clearance of bacterial infection. Thus, TLRs are key components involved in the innate defense against pathogens. Lipopolysaccharide (LPS) is an integral component of the $\mathrm{G}^{-}$bacterial cell wall, which can be recognized by TLR4, whereas CpG-dsDNA can be recognized by TLR-9 (5). TLR4 and TLR-9 have been confirmed to be overexpressed in IBD and induce Th1/Th17 differentiation (6,7). Once TLRs recognize a particular component, they recruit adaptor proteins and initiate downstream signaling cascades. According to the protein interaction information obtained from the online updated Search Tool for the Retrieval of Interacting Gene 10 database (http://string-db.org/), which has a confidence score for every protein interaction, TLR4 and TLR-9 have interactions with cluster of differentiation 40 (CD40).

The CD40/CD40L system is crucial in its involvment in the differentiation of Th1 and Th17 cells $(8,9)$. CD40 and CD40L are overexpressed in both forms of IBD $(10,11)$, indicating that the CD40/CD40L pathway has a key pathogenic role in intestinal inflammation and is a rational target for therapeutic intervention. Previous reports have shown that shutting down the CD40/CD40L system is effective in reducing inflammation in in vitro cellular systems and in in vivo animal models of experimental colitis $(12,13)$. Several signaling pathways have been coupled to CD40, for example, P38 mitogen-activated protein kinase (MAPK)/tumor necrosis factor (TNF) $\alpha$ has been shown to enlarge systemic inflammation and promote the differentiation of Th1 and Th17 cells (14), whereas signal transducer and activator of transcription (STAT)-3/interleukin 
(IL)-6 has been shown to control systemic inflammation and inhibit the differentiation of Th1 and Th17 cells (15). However, whether LPS or CpG-dsDNA affect the expression of CD40 in colonic epithelial cells, which downstream signaling is involved and what effects are induced by different signaling pathways remain to be elucidated.

In the present study, dextran sodium sulfate, which is a common agent used for the establishment of IBD in animal models, was used to injure colonic epithelial cells, and the protective effects of pretreatment with different concentrations of LPS and of CpG-dsDNA were observed. In addition, the present study examined whether pretreatment with LPS or CpG-dsDNA induces protective effects against IBD by affecting the expression CD40 and its downstream signaling.

\section{Materials and methods}

Cell culture. The human colonic epithelial cell line (HT-29) was purchased from Cell Biologics, Inc. (Chicago, IL, USA). The cell line was cultured in Dulbecco's modified Eagle's medium (DMEM; Sigma-Aldrich; Merck Millipore, Darmstadt, Germany) supplemented with $10 \%$ fetal bovine serum (Gibco; Thermo Fisher Scientific, Inc., Waltham, MA, USA), $100 \mathrm{U} / \mathrm{ml}$ penicillin and $100 \mu \mathrm{g} / \mathrm{ml}$ streptomycin at $37^{\circ} \mathrm{C}$ in $5 \% \mathrm{CO}_{2}$. At $90 \%$ confluence, the HT-29 cells, with an initial density of $1 \times 10^{5}$ cells/well, were challenged with various concentrations of microbial cell components, including LPS from Escherichia coli (E.coli O111:B4; Beyotime Institute of Biotechnology, Haimen, China) at concentrations of 50,20 and $10 \mu \mathrm{g} / \mathrm{ml}$, or CpG-dsDNA from double-stranded genomic DNA of E.coli K12 (Invivogen, San Diego, CA, USA) at concentrations of 50,20 and $10 \mu \mathrm{g} / \mathrm{ml}$ at $37^{\circ} \mathrm{C}$ for $24 \mathrm{~h}$. The cells were then stimulated with $20 \mu \mathrm{g} / \mathrm{ml}$ DSS (MP Biomedicals, Santa Ana, CA, USA) at $37^{\circ} \mathrm{C}$ for a further $24 \mathrm{~h}$.

Wound repair assay. A wound repair assay was performed, as previously described (16). Briefly, the HT-29 cells were cultured in 12-well plates to $90 \%$ confluence and a wound was made in the confluent monolayer by mechanical scraping. The wound was observed and recorded every $4 \mathrm{~h}$ for a total of $24 \mathrm{~h}$ using video microscopy (Olympus Corporation, Tokyo, Japan). The repair index was calculated according to a linear regression equation of the remaining wound area over time.

Flow cytometric analysis. The cells from a six-well plate were harvested and washed twice in phosphate-buffered saline (PBS), counted, and re-suspended in $1 \%$ BSA (RayBiotech, Norcross, GA, USA) containing $0.01 \% \mathrm{NaN}_{3}$. For flow cytometric analysis, $10^{6}$ cells were incubated with mouse anti-human CD40-PE antibody (dilution, 1:200; cat. no. 9821-09; SouthernBiotech, Birmingham, AL, USA) at $37^{\circ} \mathrm{C}$ for $1 \mathrm{~h}$. The cells were then washed with washing buffer three times, re-suspended in $0.5 \mathrm{ml} \mathrm{PBS}$ and analyzed using a flow cytometer (Beckman Coulter, Inc., Brea, CA, USA). All incubations were performed on ice. Anti-CD11b (dilution, 1:200; cat. no. FHP011b-100; 4A Biotech Co., Ltd., Beijing, China) was used for isotype controls. The expression levels of antigen were calculated as a percentage of positive cells in the total cells using CytExpert software version 1.1.10.0 (Beckman Coulter, Inc.).
Reverse transcription-quantitative polymerase chain reaction $(R T-q P C R)$ analysis. RNA was extracted from the cell samples using TRIzol reagent (Takara Bio, Inc., Otsu, Japan). The RT-qPCR analysis was performed using cDNA generated from $3 \mu \mathrm{g}$ of total RNA using the SuperScript II Reverse Transcriptase kit (Takara Bio, Inc.). The following PCR primer sequences were used: STAT-3, forward 5'-CATACC CTTGTGGATCGTGCACG-3' and reverse 5'-GGCAAAGGC TTACTGATAAACTTGA-3'; P38 MAPK, forward 5'-CGC ATC TGA ACTGTTGTAGGGTG-3' and reverse 5'-TGT CTTTGTGGGAGGGTAAGACA-3'; 18S, forward 5'-GGT TCCTTTGGTCGCTCGC-3' and reverse 5'-CTGCTGCCT TCCTTGGATGTG-3'. The reactions were performed using SYBR Green Master mix (Takara Bio, Inc.) and quantitatively measured using an ABI Prism 7900HT Sequence Detection system (Thermo Fisher Scientific, Inc.). The following thermal cycler parameters were used: A single cycle of $95^{\circ} \mathrm{C}$ for $30 \mathrm{sec}$ and 40 cycles of denaturation $\left(95^{\circ} \mathrm{C}\right.$ for $\left.15 \mathrm{sec}\right)$ and combined annealing/extension $\left(60^{\circ} \mathrm{C}\right.$ for $\left.45 \mathrm{sec}\right)$. The relative mRNA expression of target genes was normalized with that of the endogenous 18S control gene (Applied Biosystems; Thermo Fisher Scientific, Inc.) (17).

Western blot analysis. The cells were disrupted by homogenization on ice and centrifuged at 12,000 $\mathrm{g}$ for $30 \mathrm{~min}$ at $4^{\circ} \mathrm{C}$, followed by collection of supernatants. Equal quantities of protein $(80 \mu \mathrm{g})$ were separated by $10 \%$ SDS-PAGE and transferred onto a nitrocellulose membrane. The membranes were blocked in $5 \%(\mathrm{w} / \mathrm{v})$ skim milk and incubated with antibodies against human p-STAT3 (dilution, 1:1,000; cat. no. ab30647; Abcam, Cambridge, UK), STAT-3 (dilution, 1:1,000; cat. no. 9939; Cell Signaling Technology, Inc., Danvers, MA, USA), phosphorylated (p)-P38 MAPK (dilution, 1:1,000; cat. no. sc-101759; Santa Cruz Biotechnology, Inc., Dallas, TX, USA), p38MAPK (dilution, 1:1,000; cat. no. sc-7149; Santa Cruz Biotechnology, Inc.) and $\beta$-actin (dilution, 1:2,000; cat. no. sc-7210; Santa Cruz Biotechnology, Inc.), respectively. The blots were then incubated with horseradish peroxidase-conjugated secondary antibodies (dilution, 1:2,000; cat. no. sc-2054; Santa Cruz Biotechnology, Inc.) and detected using enhanced chemiluminescence (Thermo Fisher Scientific, Inc.). The quantification of protein expression was performed using AlphaEase software version 2200 (Alpha Innotech Corporation; ProteinSimple, San Jose, CA, USA). The ratios of band intensity were calculated using the value of the band intensity of the experimental protein divided by that of $\beta$-actin. Data are expressed as the mean \pm standard deviation of the mean of three replicate experiments.

Determination of the levels of IL- 6 and TNF $\alpha$. The supernatants were assayed for IL- 6 and TNF $\alpha$ using ELISA kits according to the manufacturer's protocol (R\&D Systems, Inc., Minneapolis, MN, USA). The results are expressed as $\mathrm{pg} / \mathrm{ml}$ of protein in each sample.

Effects of MAPK and STAT-3 inhibitors on bacterial component-induced mechanisms. The HT-29 cells $\left(5 \times 10^{5}\right.$ cells/well) in 6-well plates (90\% confluence) were pretreated with LPS or CpG-dsDNA for $24 \mathrm{~h}$ and then treated with DSS for $30 \mathrm{~min}$, followed by treatment with MAPK inhibitor (SB 203580; 
Beyotine Institute of Biotechnology) to a final concentration of $500 \mathrm{nM}$ or STAT-3 inhibitor (S31-201; Santa Cruz Biotechnology Inc.) to a final concentration of $100 \mu \mathrm{M}$ at $37^{\circ} \mathrm{C}$ for $30 \mathrm{~min}$. The MAPK inhibitor, SB 203580, is a pyridinyl imidazole inhibitor widely used to inhibit the phosphorylation and activation of p38 MAPK. The STAT-3 inhibitor, S31-201, inhibits the STAT-3 transcription factor by inhibiting the phosphorylation and dimerization events necessary for activation. The cells were then subjected to protein analysis for p38 or STAT-3. Wound repair was assayed following treatment with DSS for $24 \mathrm{~h}$.

Statistical analysis. All data are expressed as the mean \pm standard deviation. The differences among groups were analyzed using one-way analysis of variance and the Bonferroni method was used for post hoc tests. Statistical analysis was performed by using the SPSS 15.0 software package (SPSS, Inc., Chicago, IL, USA). $\mathrm{P}<0.05$ was considered to indicate a statistically significant difference.

\section{Results}

Effects of LPS and CpG-dsDNA on wound repair of HT-29 cells. A wound was introduced in every well with a closure area of $\sim 2.98 \pm 0.124 \mathrm{~mm}^{2}$. Following $24 \mathrm{~h}$, the remaining wound area in the control group was decreased to zero (Fig. 1A). The repair of HT-29 cells was inhibited by LPS at concentrations of 50 and $20 \mu \mathrm{g} / \mathrm{ml}$, and inhibited by CpG-dsDNA at the concentration of $50 \mu \mathrm{g} / \mathrm{ml}$. The repair was inhibited by DSS, and either $20 \mu \mathrm{g} / \mathrm{ml}$ of LPS or $20 \mu \mathrm{g} / \mathrm{ml}$ of CpG-dsDNA were found to abrogate the inhibitory effects induced by DSS (Fig. 1B).

Pretreatment with LPS or Cp $G$-dsDNA on expression of CD40 in HT-29 cells. Treatment of the normal HT-29 cells with LPS $(50,20$ and $10 \mu \mathrm{g} / \mathrm{ml})$ or CpG-dsDNA $(50,20$ and $10 \mu \mathrm{g} / \mathrm{ml})$ produced a significant increase in the expression of CD40 in a concentration-dependent manner (Fig. 2A to $\mathrm{C} ; \mathrm{P}<0.01$ ), with no statistically significant differences between LPS and CpG-dsDNA (Fig. 2B and C). Pretreatment with LPS at 50, 20 and $10 \mu \mathrm{g} / \mathrm{ml}$ decreased the DSS-induced expression of CD40 by $31.44,38.28$ and $27.18 \%$, respectively (Fig. 2A and D). Pretreatment with CpG-dsDNA at 50, 20 and $10 \mu \mathrm{g} / \mathrm{ml}$ concentrations decreased the DSS-induced expression of CD40 by $22.45,38.77$ and $13.07 \%$, respectively, compared with the DSS group (Fig. 2A and D). As $20 \mu \mathrm{g} / \mathrm{ml}$ of LPS or CpG-dsDNA had the highest protective effects on DSS injury and the most potent inhibition of CD40 molecules, this concentration was selected for the further experiments.

Pretreatment with CpG-dsDNA or LPS promotes the production ofIL-6 and inhibits the production ofTNF $\alpha$ in DSS-treated HT-29 cells. To elucidate the protective mechanism of LPS and of CpG-dsDNA on DSS-treated HT-29 cells, ELISA was performed in a collected culture supernatant to estimate the secretory levels of TNF $\alpha$ and IL-6. The results showed that LPS $(20 \mu \mathrm{g} / \mathrm{ml})$ and CpG-dsDNA $(20 \mu \mathrm{g} / \mathrm{ml})$ promoted the secretion of TNF $\alpha$ and IL- 6 in normal HT-29 cells, with no statistically significant differences between them (Fig. 3). The DSS-treated HT-29 cells expressed a relatively higher

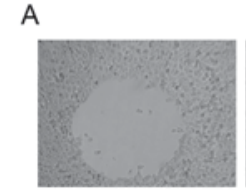

B

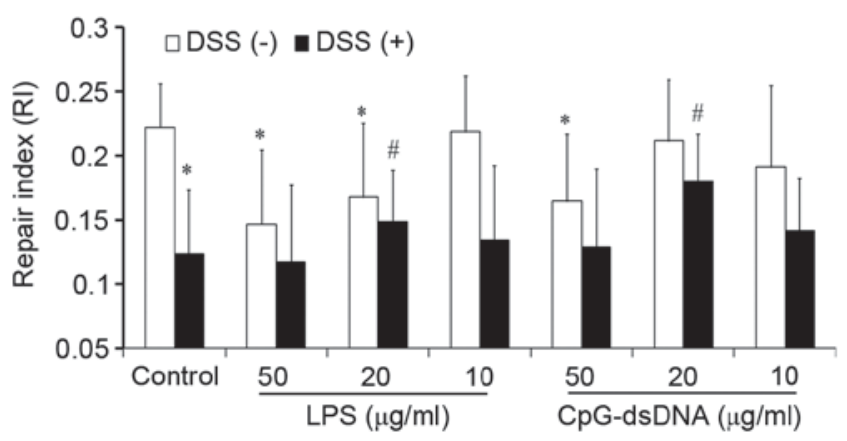

Figure 1. Effects of pretreatment with LPS or CpG-dsDNA on wound repair were examined using video analyses following mechanical injury $(n=4)$. (A) Representative images of wound repair in the control group (magnification, x100). (B) Repair of HT-29 was inhibited by DSS, which was reversed by $20 \mu \mathrm{g} / \mathrm{ml}$ of LPS or CpG-dsDNA pretreatment. ${ }^{*} \mathrm{P}<0.05$, vs. control group; ${ }^{\#} \mathrm{P}<0.05$, vs. DSS group. LPS, lipopolysaccharide; DSS, dextran sodium sulfate.

level of TNF $\alpha$ and relatively lower level of IL-6, compared with the cells pretreated with LPS or CpG-dsDNA $(\mathrm{P}<0.05)$. Pretreatment with LPS $(20 \mu \mathrm{g} / \mathrm{ml})$ or CpG-dsDNA $(20 \mu \mathrm{g} /$ $\mathrm{ml})$ decreased expression of the pro-inflammatory cytokine TNF $\alpha$ and increased the secretion of IL-6, compared with the DSS group (Fig. 3).

Pretreatment with LPS or CpG-dsDNA inhibits p38 MAPK and promotes STAT-3 in DSS-treated HT-29 cells. MAPK signaling is important during inflammatory responses. To analyze the role of MAPK in the cells, HT-29 cells were cultured with or without DSS following pretreatment with LPS $(20 \mu \mathrm{g} / \mathrm{ml})$ or CpG-dsDNA $(20 \mu \mathrm{g} / \mathrm{ml})$. The cells were the subjected to mRNA analysis and protein analysis for activated p38. The data showed that LPS and CpG-dsDNA promoted the mRNA expression of MAPK in normal HT-29 cells $(\mathrm{P}<0.01)$. An increased mRNA expression of $\mathrm{p} 38$ was found in DSS-treated HT-29, which was significantly inhibited by LPS or CpG-dsDNA pretreatment (Fig. 4A; $\mathrm{P}<0.05$ ). The protein expression and activation of P38 exhibited the same tendancy as the mRNA expression.

The present study hypothesized that the LPS- or CpG-dsDNA-mediated protection of epithelial cells is essentially through the activation of STAT3. To evaluate the role of the STAT3 cascade in the LPS- or CpG-dsDNA-mediated protective mechanisms, RT-qPCR analysis and western blot analysis were performed for STAT3. The data showed that LPS and CpG-dsDNA promoted the mRNA expression of STAT-3 in normal HT-29 cells $(\mathrm{P}<0.01)$. However, the DSS-stimulated HT-29 cells pretreated with LPS $(20 \mu \mathrm{g} / \mathrm{ml})$ or CpG-dsDNA $(20 \mu \mathrm{g} / \mathrm{ml})$ led to increased mRNA expression levels of STAT3, compared with that in the DSS group (Fig. 4B; $\mathrm{P}<0.05)$. The protein expression and activation of STAT-3 exhibited the same tendency as the mRNA expression. These 
A
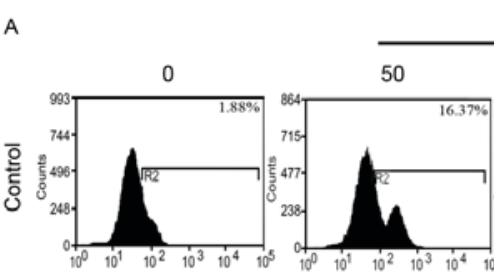

LPS
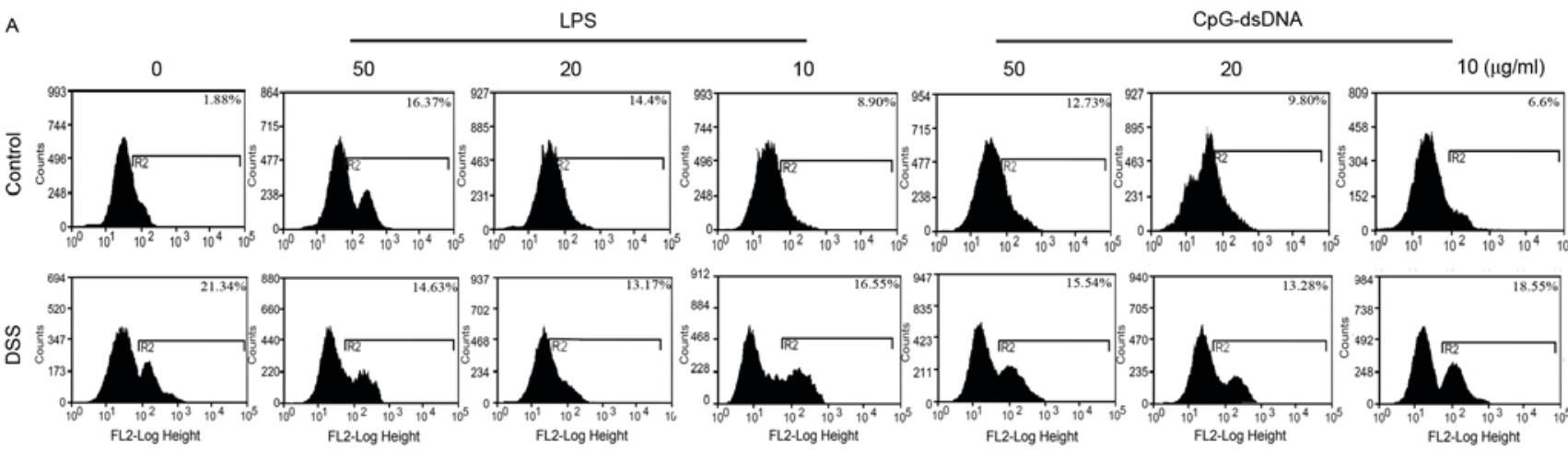

B
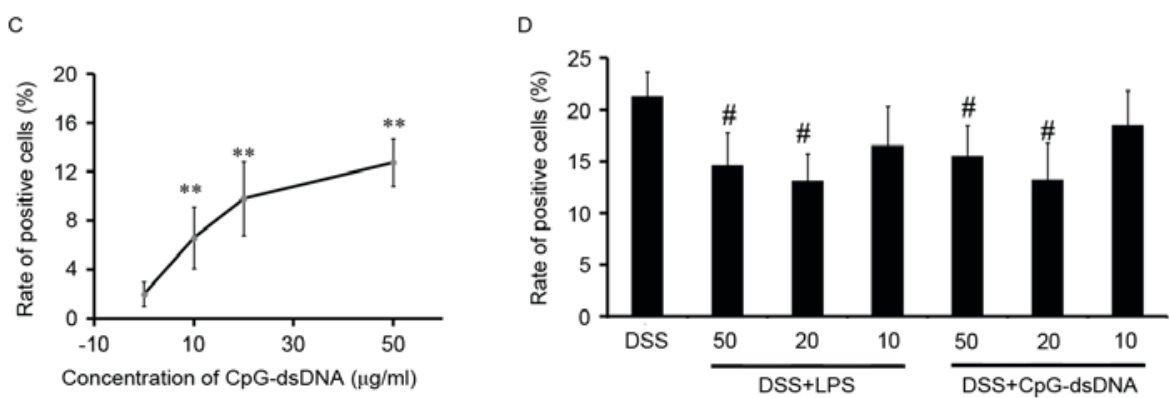

Figure 2. Effects of pretreatment with LPS or CpG-dsDNA on the expression of CD40 was assayed using flow cytometeric analysis ( $\mathrm{n}=6$ ). (A) Representative images showed that LPS and CpG-dsDNA produced a concentration-dependent increase of the expression of CD40. (B) LPS produced a concentration-dependent increase on the expression of CD40 in normal HT-29 cells. (C) CpG-dsDNA produced a concentration-dependent increase of the expression of CD40 in normal HT-29 cells. (D) Pretreatment with LPS or CpG-dsDNA decreased DSS-induced expression of CD40. ${ }^{* *} \mathrm{P}<0.01$, vs. control group; ${ }^{*} \mathrm{P}<0.05$, vs. DSS group. LPS, lipopolysaccharide; DSS, dextran sodium sulfate; CD40, cluster of differentiation 40.
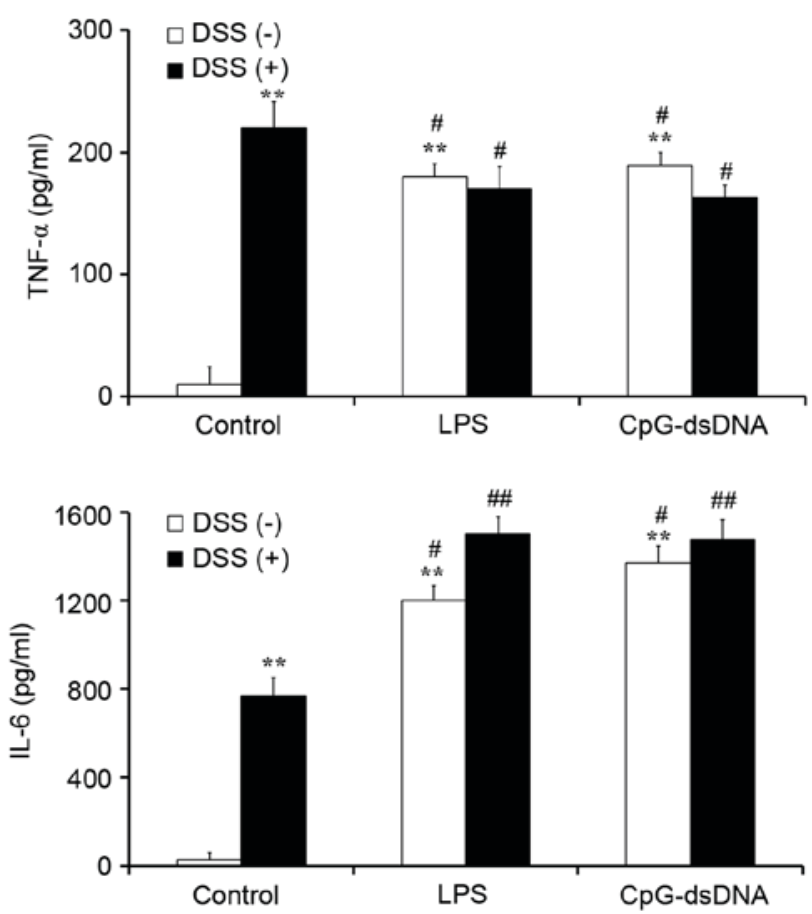

Figure 3. Effects of pretreatment with LPS or CpG-dsDNA on production of IL-6 and TNF $\alpha$ was assayed using ELISA ( $\mathrm{n}=6)$. LPS and CpG-dsDNA promoted the secretion of TNF $\alpha$ and IL- 6 in normal HT-29 cells, with no statistically significant differences between them. The DSS-treated HT-29 cells induced a relatively higher level of TNF $\alpha$ and relatively lower level of IL-6, compared with the LPS or CpG-dsDNA-treated groups. Pretreatment with LPS $(20 \mu \mathrm{g} / \mathrm{ml})$ or CpG-dsDNA $(20 \mu \mathrm{g} / \mathrm{ml})$ decreased secretion of TNF $\alpha$ and increased secretion of IL-6, compared with secretion in the DSS group. ${ }^{* *} \mathrm{P}<0.01$, vs. control group; ${ }^{*} \mathrm{P}<0.05$ and ${ }^{\# \#} \mathrm{P}<0.01$, vs. DSS group. LPS, lipopolysaccharide; DSS, dextran sodium sulfate; TNFa, tumor necrosis factor $\alpha$; IL-6, interleukin-6. data suggested that the inhibition of p38MAPK signaling and activation of STAT3 signaling may be responsible for the protective effects.

Effects of MAPK and STAT-3 inhibitors on the protective effects of LPS or Cp G-dsDNA pretreatment. In order to determine the effects of MAPK or STAT-3 inhibitors on wound repair of the HT-29 cells, the HT-29 cells were pretreated with MAPK inhibitor (SB 203580; $500 \mathrm{nM}$ ) or STAT-3 inhibitor (S31-201; $100 \mu \mathrm{M}$ ) for $30 \mathrm{~min}$ following treatment with DSS for $30 \mathrm{~min}$. The wound repair was assayed following treatment with DSS for $24 \mathrm{~h}$. The results of western blot analysis showed that the MAPK inhibitor inhibited the activation of MAPK, but had no effects on wound repair (Fig. 5A). The STAT-3 inhibitor inhibited the activation of STAT-3 and wound repair in the DSS-treated HT-29 cells (Fig. 5B).

\section{Discussion}

Previous studies have shown that defects in the function and integrity of the intestinal epithelium are important in the occurrence and development of IBD (18). Wound repair is the primary mechanism in maintaining structural and functional integrity. Luminal microbiota may exert important effects on structural and functional integrity, and microbes may have beneficial effects on the epithelium or may cause adverse effects towards the epithelium $(19,20)$. Through the use of TLRs, which recognize conserved microbial structures, epithelial cells are able to sense microbes, which lead to the inducible secretion of further mediators and corresponding $\mathrm{T}$ cell responses. 
A
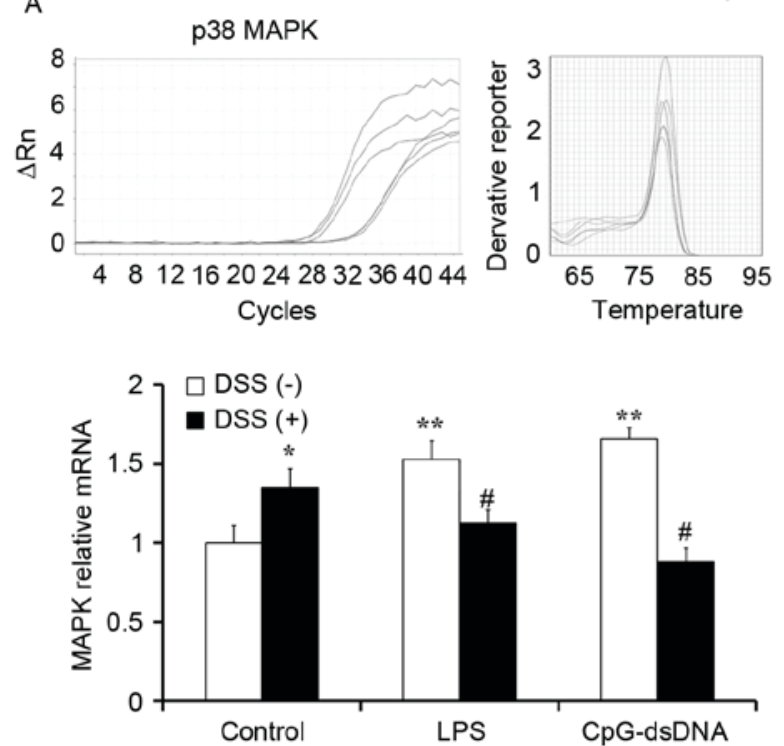

DSS

LPS

CpG-dsDNA
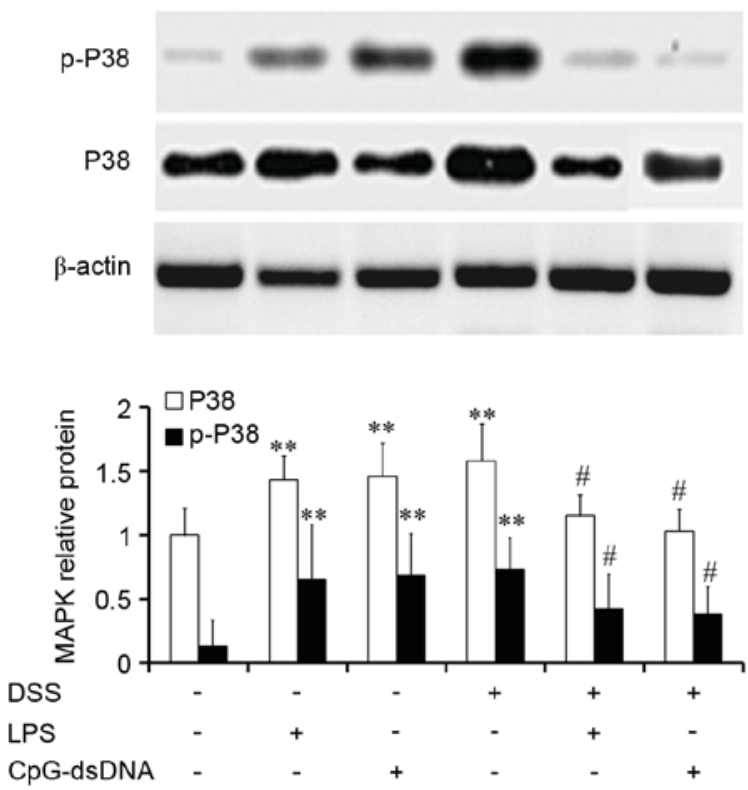

B
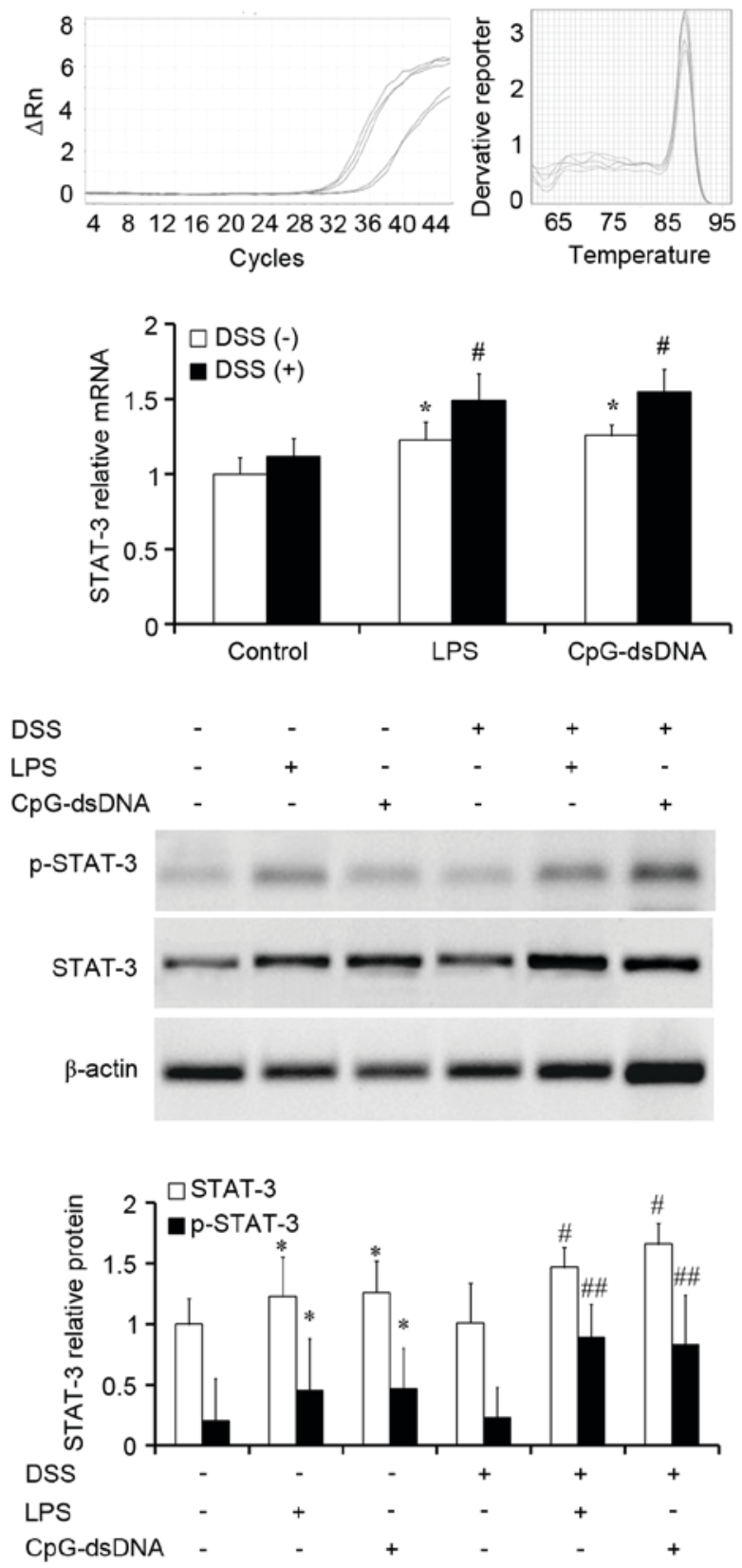

Figure 4. Expression and activation of p38 MAPK and STAT-3 determined using reverse transcription-quantitative polymerase chain reaction and western blot analyses $(n=3)$. (A) LPS and CpG-dsDNA promoted the expression and activation of MAPK in normal HT-29 cells. Increased expression and activation of p38 were observed in the DSS-treated HT-29, which was significantly inhibited by CpG-dsDNA or LPS pretreatment. (B) LPS and CpG-dsDNA promoted the expression and activation of STAT-3 in normal HT-29 cells. However, the DSS-treated HT-29 cells pretreated with CpG-dsDNA or LPS exhibited increased expression and activation of STAT3, compared with the DSS group. ${ }^{*} \mathrm{P}<0.05$ and ${ }^{* *} \mathrm{P}<0.01$, vs. control group; ${ }^{\#} \mathrm{P}<0.05$ and ${ }^{\# \#} \mathrm{P}<0.01$, vs. DSS group. LPS, lipopolysaccharide; DSS, dextran sodium sulfate; MAPK, mitogen-activated protein kinase; STAT-3, signal transducer and activator of transcription-3; p-, phosphorylated.

The upregulation of CD40 in the microcirculation of IBD-affected mucosa is of particular interest as the CD40 pathway is intimately involved in exaggerated inflammation. The stimulation of CD40-bearing cells triggers multiple inflammatory signals, resulting in leukocyte recruitment and amplification of tissue injury $(21,22)$. CD40 molecules stimulate the activation of multiple signaling pathways. TNF-receptor associated factor or Janus kinase, respectively, interact with different structural domains in the cytoplasm of CD40 and mediate the activation of NF- $\kappa$ B, STATs and
P38MAPK, and DNA dependent protein kinase $(23,24)$. In the present study, it was observed that LPS and CpG-dsDNA activated CD40, MAPK/TNF $\alpha$ and STAT-3/IL-6, and inhibited wound repair in normal HT-29 cells. When the cells were treated with DSS, there was an absolute upregulation of CD40 and MAPK/TNF $\alpha$ and inhibiton of wound repair. However, when the cells were pretreated with LPS or CpG-dsDNA, there was a downregulation of CD40 and MAPK/TNF $\alpha$, and an upregulation of STAT-3/IL-6, compared with the DSS-injured cells. These results suggested that there was a 

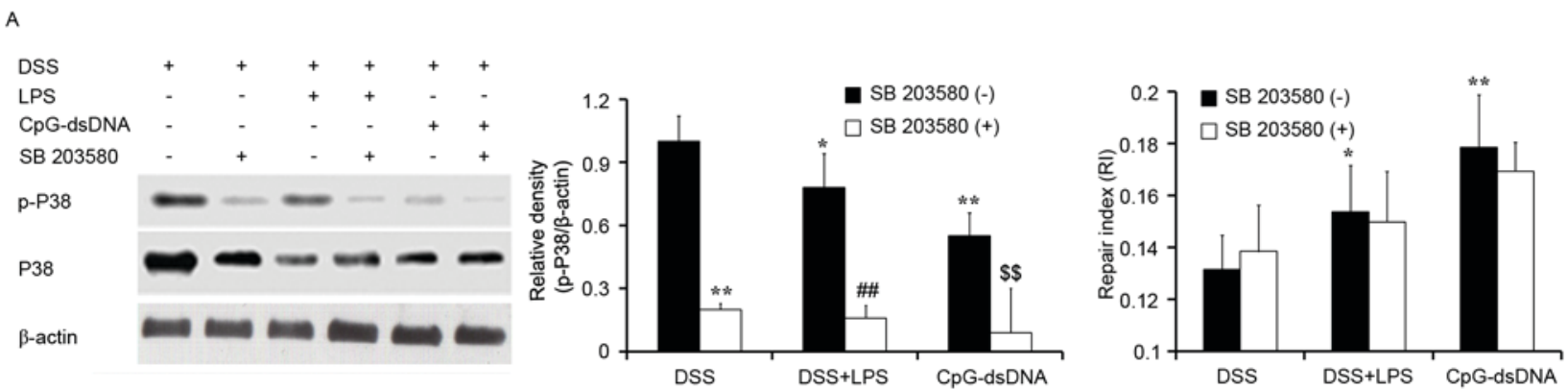

B
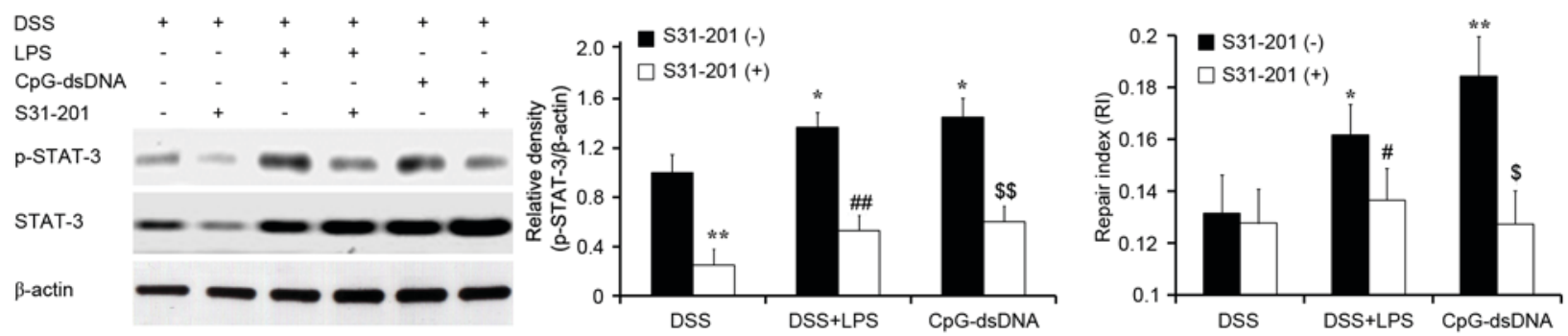

Figure 5. Effects of MAPK and STAT-3 inhibitors on wound repair of HT-29 cells with LPS or CpG-dsDNA pretreatment (n=4). (A) MAPK inhibitor inhibited the activation of MAPK, but had no effect on wound repair. (B) STAT-3 inhibitor inhibited the activation of STAT-3 and wound repair in the DSS-injured HT-29 cells. ${ }^{* *} \mathrm{P}<0.01$ and ${ }^{*} \mathrm{P}<0.05$, vs. DSS group without inhibitors; ${ }^{\# \#} \mathrm{P}<0.01$ and ${ }^{\#} \mathrm{P}<0.05$, vs. DSS+LPS group without inhibitors; ${ }^{\text {; }} \mathrm{P}<0.01$ and ${ }^{\mathrm{S}} \mathrm{P}<0.05$, vs. DSS+CpG-dsDNA group without inhibitors. LPS, lipopolysaccharide; DSS, dextran sodium sulfate; MAPK, mitogen-activated protein kinase; STAT-3, signal transducer and activator of transcription-3; p-, phosphorylated.

complex interaction between bacterial and chemical factors, and that STAT-3/IL-6 mediated the promoting wound repair induced by pretreatment of bacterial components.

In conclusion, the results of the present study demonstrated that LPS and CpG-dsDNA can provoke preadaptation to DSS-induced colitis. This preadaptation was accompanied by the activation of STAT-3. Bacterial components may offer potential as a strategy for the therapeutic prevention of IBD.

\section{References}

1. de Mattos BR, Garcia MP, Nogueira JB, Paiatto LN Albuquerque CG, Souza CL, Fernandes LG, Tamashiro WM and Simioni PU: Inflammatory bowel disease: An overview of immune mechanisms and biological treatments. Mediators Inflamm 2015: 493012, 2015.

2. Chassaing B, Koren O, Carvalho FA, Ley RE and Gewirtz AT: AIEC pathobiont instigates chronic colitis in susceptible hosts by altering microbiota composition. Gut 63: 1069-1080, 2014.

3. Sahay B, Ge Y, Colliou N, Zadeh M, Weiner C, Mila A, Owen JL and Mohamadzadeh M: Advancing the use of Lactobacillus acidophilus surface layer protein A for the treatment of intestinal disorders in humans. Gut Microbes 6: 392-397, 2015.

4. Zhu J, Wang Y, Yang F, Sang L, Zhai J, Li S, Li Y, Wang D, Lu C and Sun X: IL-33 alleviates DSS-induced chronic colitis in C57BL/6 mice colon lamina propria by suppressing Th17 cell response as well as Th1 cell response. Int mmunopharmacol 29: 846-853, 2015

5. Smyth K, Garcia K, Sun Z, Tuo W and Xiao Z: TLR agonists are highly effective at eliciting functional memory CTLs of effector memory phenotype in peptide immunization. Int Immunopharmacol 15: 67-72, 2013.

6. Saito K, Katakura K, Suzuki R, Suzuki T and Ohira H: Modulating Toll-like receptor 4 signaling pathway protects mice from experimental colitis. Fukushima J Med Sci 59: 81-88, 2013.

7. Berkowitz D, Peri R, Lavy A and Kessel A: Increased Toll-like receptor 9 expression by $\mathrm{B}$ cells from inflammatory bowel disease patients. Hum Immunol 74: 1519-1523, 2013.
8. Koguchi Y, Buenafe AC, Thauland TJ, Gardell JL, Bivins-Smith ER, Jacoby DB, Slifka MK and Parker DC: Preformed CD40L is stored in Th1, Th2, Th17, and T follicular helper cells as well as CD4+8-thymocytes and invariant NKT cells but not in Treg cells. PLoS One 7: e31296, 2012.

9. Iezzi G, Sonderegger I, Ampenberger F, Schmitz N, Marsland BJ and Kopf M: CD40-CD40L cross-talk integrates strong antigenic signals and microbial stimuli to induce development of IL-17-producing CD4+ T cells. Proc Natl Acad Sci USA 106: 876-881, 2009.

10. Senhaji N, Kojok K, Darif Y, Fadainia C and Zaid Y: The contribution of CD40/CD40L axis in inflammatory bowel disease: An update. Front Immunol 6: 529, 2015.

11. Borcherding F, Nitschke M, Hundorfean G, Rupp J, von Smolinski D, Bieber K, van Kooten C, Lehnert H, Fellermann K and Büning J: The CD40-CD40L pathway contributes to the proinflammatory function of intestinal epithelial cells in inflammatory bowel disease. Am J Pathol 176: 1816-1827, 2010.

12. Arranz A, Reinsch C, Papadakis KA, Dieckmann A, Rauchhaus U, Androulidaki A, Zacharioudaki V, Margioris AN, Tsatsanis C and Panzner S: Treatment of experimental murine colitis with CD40 antisense oligonucleotides delivered in amphoteric liposomes. J Control Release 165: 163-172, 2013.

13. Gao D, Wagner AH, Fankhaenel S, Stojanovic T, Schweyer S, Panzner S and Hecker M: CD40 antisense oligonucleotide inhibition of trinitrobenzene sulphonic acid induced rat colitis. Gut 54: 70-77, 2005.

14. Lee JW, Wang P, Kattah MG, Youssef S, Steinman L, DeFea K and Straus DS: Differential regulation of chemokines by IL-17 in colonic epithelial cells. J Immunol 181: 6536-6545, 2008.

15. Ng HP, Burris RL and Nagarajan S: Attenuated atherosclerotic lesions in apoE-Fcy-chain-deficient hyperlipidemic mouse model is associated with inhibition of Th17 cells and promotion of regulatory T cells. J Immunol 187: 6082-6093, 2011.

16. Tan YR, Qi MM, Qin XQ, Xiang Y, Li X, Wang Y, Qu F, Liu HJ and Zhang JS: Wound repair and proliferation of bronchial epithelial cells enhanced by bombesin receptor subtype 3 activation. Peptides 27: 1852-1858, 2006.

17. Livak KJ and Schmittgen TD: Analysis of relative gene expression data using real-time quantitative PCR and the 2(-Delta Delta C(T)) method. Methods 25: 402-408, 2001.

18. Frosali S, Pagliari D, Gambassi G, Landolfi R, Pandolfi F and Cianci R: How the intricate interaction among toll-like receptors, microbiota and intestinal immunity can influence gastrointestinal pathology. J Immunol Res 2015: 489821, 2015. 
19. ButtóLF, Schaubeck M and HallerD: Mechanisms of microbe-host interaction in Crohn's disease: Dysbiosis vs. Pathobiont selection. Front Immunol 6: 555, 2015.

20. Wang L, Wu G, Qin X, Ma Q, Zhou Y, Liu S and Tan Y: Expression of nodal on bronchial epithelial cells influenced by lung microbes through DNA methylation modulates the differentiation of T-Helper cells. Cell Physiol Biochem 37: 2012-2022, 2015.

21. Greene JA, Portillo JA, Lopez Corcino Y and Subauste CS: CD40-TRAF signaling upregulates CX3CL1 and TNF- $\alpha$ in human aortic endothelial cells but not in retinal endothelial cells. PLoS One 10: e0144133, 2015.
22. Wang W, Bai L, Qiao H, Lu Y, Yang L, Zhang J, Lin R, Ren F, Zhang J and Ji M: The protective effect of fenofibrate against TNF- $\alpha$-induced CD40 expression through SIRT1-mediated deacetylation of NF- $\kappa \mathrm{B}$ in endothelial cells. Inflammation 37: 177-185, 2014.

23. Seibold K and Ehrenschwender M: p62 regulates CD40-mediated $\mathrm{NF} \kappa \mathrm{B}$ activation in macrophages through interaction with TRAF6. Biochem Biophys Res Commun 464: 330-335, 2015.

24. Chakraborty S, Srivastava A, Jha MK, Nair A, Pandey SP, Srivastava N, Kumari S, Singh S, Krishnasastry MV and Saha B: Inhibition of CD40-induced N-Ras activation reduces leishmania major infection. J Immunol 194: 3852-3860, 2015. 